\title{
Molecular diagnosis of new isolate of tomato yellow leaf curl virus in Iraq
}

\author{
Ali Alabde, Osamah Alisawi*, Fadhal Al Fadhal
}

Department of Plant Protection, Faculty of Agriculture, Kufa University, Najaf, Iraq

*Corresponding Author

Osamah Alisawi

Department of Plant Protection

University of Kufa

Najaf-Iraq

Tel: 009647816353396

E-mail: osama.alisawi@uokufa.edu.iq

Keywords: Tomato yellow leaf curl virus; next generation sequencing; bioinformatics; tomato genome.

\section{Abstract}

Tomato yield and quality in Iraq have been threatened by a variable range of infections caused by tomato yellow leaf curl virus. In previous studies, the TYLCV isolates were partially characterized using molecular tests for small fragments not the entire length of the virus. Sample of TYLCV-infected tomato has applied in this study to diagnose complete sequence of TYLCV isolate. Three sets of primers that belong to three well-identified strains in Iraq were used in a PCR technique and interestingly the results were negative. A new Iraqi isolate has been characterized as a first novel Iraqi isolate detected ever using next generation (NGS) and bioinformatics techniques. The NGS platform has produced about 78,232,062 paired reads of the TYLCV-infected tomato var. Oula F1. The complete raw reads of the infected variety have been analyzed using RepeatExplorer pipeline and Map to reference. The full sequence of TYLCV was reconstructed and extracted to consist of $2770 \mathrm{nt}$ and then deposited in Genbank under accession 
number MT583814. Copy numbers and genome proportion of this sequence have been calculated that were 3523 and 0,086\% respectively. Phylogenetic analyses of full nucleotide sequences confirmed close relationship to Iranian isolate (TYLCV-Kahnooj) than other published viruses. Additionally, a and $\beta$ DNA satellites have not discovered in the TYLCVinfected sample.

\section{Introduction}

37 The family Geminiviridae is recently divided into seven genera: Becurtovirus, Begomovirus, Curtovirus, Eragrovirus, Mastrevirus, Topocuvirus and Tur ncurtovirus. Host range, insect vector, genome organization and genome-wide pairwise sequence identities have been applied to classify this family (Varsani et al., 2017). Tomato yellow leaf curl virus (TYLCV) belongs to genus Begomovirus and has a monopartite singlestranded DNA (ssDNA) encapsidated in geminate particles. TYLCV is transmitted by the whitefly, Bemisia tabaci (Genn.) that effectively spread virus particles through persistent manner (Panno et al., 2016). The disease caused by this virus is the most important disease on tomato in Iraq and worldwide (Mansoor et al., 2003; Salati et al., 2002; Al-Kuwaiti et al., 2013). Infected plants become stunted with chlorotic leaves, curled-up margins, and abscised flowers. Since the first infection was recorded in Israel 1939-1940, multiple regions have been identified to have isolates from this virus over the world and classified to different viral species (Antignus and Cohen 1994; Delatte et al., 2004; Pico et al., 1996; Polston and Anderson 1997). Tomato yellow leaf curl Sardinia virus TYLCSV infected tomatoes in Israel and Sardinia, and was the first sequenced isolate in 1991(Kheyr-Pour et al., 1991; Navot et al., 1991), and since that date many isolates have been sequenced from various locations (Moriones and Navas-Castillo 2000). In Iraq, the disease was detected based on symptoms assay and serological tests. Recently, most popular molecular works on this virus have been achieved by PCR based on amplified short

55 fragments of TYLCV genome such as coat protein domain (Al-Ani et al., 2010; Reddy et al., 2005; Maruthi et al., 2007). Further, many tomato genotypes have been screened against TYLCV isolates to characterize similarities and differences through these genotypes (Al Tamimi, 2020). TYLCV has been isolated not only from tomato but also from various plants such as 
60 infection like Malva parviflora, Chenopodium murale and Chenopodium quinoa (Al- Jubouri et

61 al ., 2014). Al-Kuwaiti et al (2013) have reported complete sequence of TYLCV that showed

$6299 \%$ identity to Spain strain (Acc. AJ489258) confirming its existence in Iraq. In this study, we

63 utilized next generation sequencing and bioinformatics techniques for the first time in Iraq to

64 find out new isolate with complete sequence of TYLCV. Furthermore, phylogeny analyses have

65 been performed to understand how these isolates related to each other.

66

67 Plant material

68

69

70

71

72

73

74

75

76

77

78

79

From open fields of Najaf governorate, the main region of tomato production in Iraq, fresh and young leaves of TYLCV-infected tomato variety Oula F1 (Seminis Seeds Company, USA) were harvested. This variety is considered the most popular and TYLCV-sensitive commercial variety of tomato in the middle of Iraq.

\section{DNA isolation, PCR and NGS sequencing}

To extract the DNA, the young leaves (about $2 \mathrm{gm}$ ) of the infected tomato were applied using cetyl-trimethylammonium bromide $(\mathrm{CTAB})$ method with minor modifications (Doyle and Doyle 1990). Three sets of primers that belong to strains of TYLCV-IS, TYLCV-ES and TYLCV-Mld were applied in a PCR technique to check their infection within examined sample (Table 1) (Anfoka et al., 2005).

Table 1. Three primers of main strains of TYLCV in Iraq that used to amplify and characterize virus sequence in the examined sample.

\begin{tabular}{|c|c|c|c|}
\hline Primers & Sequence (5'-3') & $\begin{array}{c}\text { Size } \\
\text { (bp) }\end{array}$ & Strains \\
\hline TYv2337 & ACGTAGGTCTTGACATCTGTTGAGCTC & 634 & TYLCV-IS \\
TYc138 & AAGTGGGTCCCACATATTGCAAGAC & Israel \\
\hline TYAlmv2516 & TTTTATTTGTTGGTGTTTGTAGTTGAAG & 433 & TYLCSV-ES \\
TYAlmcl15 & ATATTGATGGTTTTTCAAAACTTAGAAG & & Spain Almeria \\
\hline
\end{tabular}




\begin{tabular}{|c|c|c|c|}
\hline TYv2664 & ATTGACCAAGATTTTTACACTTATCCC & 316 & TYLCV - mld \\
TYc138 & AAGTGGGTCCCACATATTGCAAGAC & Normal mild \\
\hline
\end{tabular}

81 PCR conditions were an initial denaturation of $10 \mathrm{~min}$ at $95^{\circ} \mathrm{C}, 49$ cycles of $30 \mathrm{~s}$ at $95^{\circ} \mathrm{C}, 20 \mathrm{~s}$ at $82 \quad 55-63^{\circ} \mathrm{C}$ and $30 \mathrm{~s}$ at $72^{\circ} \mathrm{C}$ followed by a final extension of $30 \mathrm{~s}$ at $72^{\circ} \mathrm{C}$. To obtain the whole 83 genome sequence, the extracted genomic DNA sample was sent to sequencing at DNA-link 84 Company, Republic of Korea. The genome was sequenced by using the Novaseq6000 2x150bp reads technique and application WGS (PCR Free550) based on the manufacturer's procedure.

RepeatExplorer program

To collect virus sequences from the whole data (NGS) of infected tomato, RepeatExplorer pipeline was applied to recognize these kinds of sequences in forms of clusters within repetitive DNA blocks (Novák et al. 2013). The targeted clusters of RepeatExplorer were extracted, and then Repbase dataset (Jurka et al. 2005), and Basic Local Alignment Search Tool (Altschul et al. 1990) were used to identify contigs of each cluster. Furthermore, the extracted sequences were mapped to well-identified plant virus sequences from DPVweb (Adams and Antoniw 2005).

Using Geneious program V. 11 (Kearse et al. 2012), the raw reads were assembled against TYLCV Iraq (Acc. JQ354991.1) as a reference sequence that diagnosed by Al-Kuwaiti et al. (2013) and then consensus sequence was collected. Mapping to reference was repeated against consensus sequence (TYLCV) to confirm and obtain the actual number of assembled reads. Also, the raw reads were applied to assemble against a and $\beta$ DNA satellites. The outcomes showed in a report that has a number of assembled reads and total used reads in addition to the frequent overlapped reads. This data used to calculate copy numbers (Number of assembled reads $\mathrm{x}$ read length/reference sequence length) and genome proportions (Number of assembled reads / numbers of total NGS reads x 100) (Mustafa et al. 2018). Finally, the two consensus sequences from RepeatExplorer and Map to reference were aligned using pairwise alignment in Geneious program to collect the right length of TYLCV isolate. 
Phylogenetic analysis

The maximum likelihood (ML) method was applied to find phylogeny model using MEGA7 (Tamura et al. 2013). The Geneious program V. 11 (Kearse et al. 2012) was used for alignment and optimized manually. The entire nucleotide sequences of 13 main TYLCV isolates including our isolate of interest, Kahnooj and Iraq isolates were applied to phylogeny study. ClustalW alignment was used for extracting sequences about $2770 \mathrm{nt}$ for each. The phylogenetic tree reconstructed using General Time Reversible (GTR). Bayesian phylogeny inference was used for analysis with Bayesian inference of phylogeny (MrBayes 3.2.6) (Huelsenbeck and Ronquist 2001).

\section{Results}

The extracted DNA concentration and quality were $418 \mathrm{ng} \backslash \mathrm{ml}$ and 1.92 which was in a high quality level for sequencing approach (Fig. 1. A). PCR has surprisingly failed to get amplified sequences for the three TYLCV isolates indicating that our sample has probably a new virus sequence. High quality raw reads have been obtained from NGS Illumina platform with about 78,232,062 paired reads; 150 bp read length and 36.9\% GC content (Fig. 1. B).

RepeatExplorer has been clustered the whole uploaded raw reads that showed tandemly repeated sequences, TYLCV sequences involved in cluster number 76 as a putative satellite with a genome proportion $0,084 \%$ and the consensus sequence was 2763 nt (Fig. 1. C). On the other side, the report of Map to reference revealed that 65,303 reads have been assembled to count genome proportion and copy numbers of the isolate that were 0,086\% and 3523 respectively whereas the consensus sequence was $2770 \mathrm{nt}$. In order to obtain complete sequence, the aligned consensus sequences from both RepeatExplorer and Map to reference showed 100\% similarity and the longest sequence was extracted. Lastly, we determined $2770 \mathrm{nt}$ of TYLCV and named as Najaf isolate and then deposited in Genbank under accession number MT583814.1.

Phylogenetic analyses showed what we have proven earlier by pairwise alignment between Najaf isolate and each of Kahnooj and Iraq isolates. Kahnooj was most likely similar to Najaf isolate than Iraq. TYLCV nucleotide and amino acid sequence alignments showed that Najaf isolate is 
135 136

137

138

139

closely related to Kahnooj isolate the Iranian TYLCV in $93.8 \%$ pairwise identity while it was 90.3\% with Iraq isolate (Fig. 2). However, polymorphic sequences have shown higher rate in intergenic region (IR) (75\%), V2 (91.9\%), C1 (Rep) (93.1\%), and C4 (88.3\%) than other coding regions V1 (97.3\%), C3 (95.9\%) and C2 (96.5\%).

Our research has been extended trying to find DNA-a and $\beta$ satellites using Map to reference tool but we did not get any positive hits.

\section{Discussion}

The deep sequencing of whole genome sequencing technique has revolutionized genomic research collecting a massive data of the host genome with complete sequences of cellular components. Additionally, this method is considered as unbiased approach to detect plant viruses with no previous knowledge about the suspected elements. The NGS technique does not use specific primers, antibodies, and virus-specific reagents to diagnose pathogenic viruses (Adams et al., 2009). In this method, full image of plant viruses and complex infection could be investigated in the host genome unlikely to biased methods that focus on almost one expected virus (Jones et al., 2017). In Iraq, most of molecular tests concentrated on partial sequences of TYLCV such as coat protein domain to detect the virus and apply these amplified parts in multiple alignments and phylogeny analyses. The only full-length sequenced of this virus from Iraq was Iraq isolate (JQ354991.1) that achieved by Al-Kuwaiti et al (2013) and named as TYLCV Iraq but it shared 99\% similarity to Spain strain (Acc. AJ489258), Reunion Islands (Acc. AM409201) and Mauritius (Acc. HM448447). Additionally, Sadeq Al-Kuwaiti (2013) has applied rolling circle amplification (RCA) and non-degenerate primers to catch the full length of virus. Therefore, our new isolate is considered the first full sequenced Iraqi isolate of TYLCV with totally new data yet. We found Kahnooj isolate from Iran is closer than other isolates even from Iraq with $93.8 \%$ similarity. It is highly expected that Najaf and Kahnooj isolates are sharing the same ancestor and most likely the virus was imported into Iraq from Iran by international trading (Mali et al., 2003; Gibbs et al., 2008; Al-Kuwaiti 2013).

Mapping reads to the reference has revealed the estimated copy numbers of this virus was 3523 within infected cell. Copy number value has been always considered as a good sign for variation 
164

165

166

167

168

169

170

171

172

173

174

175

176

177

178

179

180

181

182

183

184

185

186

187

188

189

190

191

and variability of endogenous components within host genome especially transposable elements including viruses (Mustafa et al. 2018; Alisawi 2019). Interestingly, this is one of NGS and bioinformatics benefits to calculate copy numbers of the components of interest and this approach has been applied in many studies to predict viral copies (Yang et al., 2017; Alisawi 2019). So far, the number of copies indicates virus particles indeed infected the host genome. In fact, this little amount of copies strongly explains the early stage of symptoms emerging in the infected sample. However, further works need to be achieved regarding isolate distribution and diversity over tomato varieties and different regions in Iraq.

We could not reveal the existence of DNA satellites in our infected sample probably due to moderate level of infection in the examined sample. A and $\beta$ DNA satellites are often associated with begomoviruses in their replication, movement within infected plant and horizontal transmission between plants, as well as involved in induction of virus symptoms and suppression of transcriptional gene silencing. This result is consistent with most published outcomes that reported the importance of DNA satellites for disease severity and inducing symptoms. However, we do expect to find these satellites in severely TYLCV-infected plants as no more researches have been covered DNA satellites in Iraq (Laufs et al., 1995; Saunders et al., 2004; Cui et al., 2005; Yang et al., 2011; Amin et al., 2011; Zhou, 2013).

\section{Conclusion}

This work concluded that whole genome sequencing technique alongside bioinformatics is highly recommended to detect complete sequence of TYLCV isolate within infected tomato genome raw reads. Consequently, a clear insight of virus pathway and identity has been revealed by phylogenetic analysis. More investigations need to be done for detecting full sequences of highly pathogenic plant viruses in Iraq.

\section{Conflict of Interest Statement}

The authors have no conflicts of interest to declare.

\section{Funding Sources}


There are no funding sources to report.

193

\section{Statement of Ethics}

The authors have no ethical conflicts to disclose.

Author Contributions

A.A. carried out the experiment. O.A. analyzed the NGS data and wrote the manuscript with support from F.A. F.A. helped supervise the study.

\section{References}

Adams, I. P., Glover, R. H., Monger, W. A., Mumford, R., Jackeviciene, E., Navalinskiene, M., ... \& Boonham, N., 2009. Next-generation sequencing and metagenomic analysis: a universal diagnostic tool in plant virology. Molecular plant pathology, 10(4), 537-545.

Adams M.J. \& Antoniw J.F, 2005. DPVweb: An open access internet resource on plant viruses and virus diseases. Outlooks on Pest Management 16, 268-270.

Al-Ani, R. A., Diwan, S. N. H., \& Adhab, M. A, 2010. Efficiency of Thuja orientalis and Artimisia campestris extracts to control of Potato leaf roll virus (PLRV) in potato plants. Agriculture and Biology Journal of North America, 1(4), 579-583.

Alisawi, O. N, 2019. Virus integration and tandem repeats in the genomes of Petunia (Doctoral dissertation, University of Leicester).

Al-Jubouri, A. A., Al-Fadhal, F. A., \& Samaka, H. M, 2014. Detection of Tomato yellow leaf curl virus (TYLCV) and its strains on tomato plants and host rang determine by Polymerase Chain Reaction. Kufa Journal for Agricultural Sciences, 6(4), 99-117.

Al-Kuwaiti, N.; B. Otto; C. Collins; S. Seal and Maruthi, M, 2013. Molecular characterization and first complete genome sequence of Tomato yellow leaf curl virus (TYLCV) infecting tomato in Iraq. New Disease Reports, 27: 17.

Altschul S.F., Gish W., Miller W., Myers E.W. \& Lipman D.J, 1990. Basic local alignment search tool. Journal of Molecular Biology 215, 403-410.

Al Tamimi, S. Q, 2020. Molecular identification of some isolates of Tomato yellow leaf curl 
virus and test response some tomato genotypes and their control(Doctoral dissertation, University of Kufa)( In Arabic).

Amin, I., Hussain, K., Akbergenov, R., Yadav, J. S., Qazi, J., Mansoor, S., ... \& Briddon, R. W, 2011. Suppressors of RNA silencing encoded by the components of the cotton leaf curl begomovirus-betasatellite complex. Molecular plant-microbe interactions, 24(8), 973-983.

Anfoka, G.H., Abhary, M. and Nakhla, M.K., 2005. Molecular identification of species of the Tomato yellow leaf curl virus complex in Jordan. Journal of Plant Pathology, pp.65-70.

Antignus, Y., \& Cohen, S, 1994. Complete nucleotide sequence of an infectious clone of a mild isolate of Tomato yellow leaf curl virus (TYLCV). Phytopathology, 84(7), 707-712.

Cui, X., Li, G., Wang, D., Hu, D., \& Zhou, X., 2005. A begomovirus DNA $\beta$-encoded protein binds DNA, functions as a suppressor of RNA silencing, and targets the cell nucleus. Journal of Virology, 79(16), 10764-10775.

Delatte H, Naze F, Granier M, Reynaud B, Peterschmitt M, Lett M., 2004. Tomato-infecting begomoviruses in the South Western islands of the Indian Ocean. Presented at the 4th International Geminivirus Symposium, W3-4.

Doyle J. \& Doyle J., 1990. Isolation of DNA from small amounts of plant tissues. BRL Focus $12, \mathrm{~V} 15$.

Gibbs, A. J., Ohshima, K., Phillips, M. J., \& Gibbs, M. J., 2008. The prehistory of potyviruses: their initial radiation was during the dawn of agriculture. PloS one, 3(6), e2523.

Huelsenbeck J.P. \& Ronquist F., 2001. MRBAYES: Bayesian inference of phylogenetic trees. Bioinformatics 17, 754-755.

Jones, S., Baizan-Edge, A., MacFarlane, S., \& Torrance, L., 2017. Viral diagnostics in plants using next generation sequencing: computational analysis in practice. Frontiers in Plant Science, 8, 1770.

Jurka J., Kapitonov V.V., Pavlicek A., Klonowski P., Kohany O. \& Walichiewicz J., 2005. Repbase Update, a database of eukaryotic repetitive elements. Cytogenetic and Genome Research 110, 462-467.

Kheyr-Pour A, Bendahmane M, Matzeit V, Accotto GP, Crespi S, Gronenborn B., 1991. Tomato yellow leaf curl virus from Sardinia is a whitefly-transmitted monopartite geminivirus. Nucleic Acids Res 19:6763-6769. 
Kearse M., Moir R., Wilson A., Stones-Havas S., Cheung M., Sturrock S., Buxton S., Cooper A., Markowitz S. \& Duran C., 2012. Geneious Basic: an integrated and extendable desktop software platform for the organization and analysis of sequence data. Bioinformatics 28, 1647-1649.

Laufs J., Traut W., Heyraud F., Matzeit V., Rogers S. ～G., Schell J., Gronenborn B., 1995. In vitro cleavage and joining at the viral origin of replication by the replication initiator protein of Tomato yellow leaf curl virus. Proc Natl Acad Sci U S A 92:3879-3883.

Mali, V. R., Subr, Z., \& Kudela, O., 2003. Seed transmission of como and potyviruses in faba bean and vetch cultivars introduced into Slovakia. Acta phytopathologica et entomologica hungarica, 38(1-2), 87-97.

Mansoor, S., Briddon, R. W., Zafar, Y., \& Stanley, J., 2003. Geminivirus disease complexes: an emerging threat. Trends in plant science, 8(3), 128-134.

Maruthi M, Rekha A, Mirza S, Alam S, Colvin J., 2007. PCR-based detection and partial genome sequencing indicate high genetic diversity in Bangladeshi begomoviruses and their whitefly vector, Bemisia tabaci. Virus Genes 34, 373-385.

Moriones E, Navas-Castillo J., 2000. Tomato yellow leaf curl virus, an emerging virus complex causing epidemics worldwide. Virus Res 71:123-134.

Mustafa S.I., Schwarzacher T. \& Heslop-Harrison J., 2018. Complete mitogenomes from Kurdistani sheep: abundant centromeric nuclear copies representing diverse ancestors. Mitochondrial DNA Part A, 1-14.

267 Navot N, Pichersky E, Zeidan M, Zamir D, Czosnek H., 1991. Tomato yellow leaf curl virus: a 268 whitefly-transmitted geminivirus with a single genomic component. Virology 185:151-161. web server for genome-wide characterization of eukaryotic repetitive elements from next271 generation sequence reads. Bioinformatics 29, 792-793.

272 Panno, S., Iacono, G., Davino, M., Marchione, S., Zappardo, V., Bella, P., ... \& Davino, S., 2016.

273 First report of Tomato leaf curl New Delhi virus affecting zucchini squash in an important 274 horticultural area of southern Italy. New Dis. Rep, 33(6), 2044-0588.

275 Pico B, Diez MJ, Nuez F., 1996. Viral diseases causing the greatest economic losses to the 276 tomato crop. II. The Tomato yellow leaf curl virus. Sci Hort 67:151-196.

277 Polston JE, Anderson PK., 1997. The emergence of white fly transmitted geminiviruses in 278 tomato in the Western Hemisphere. Plant Dis 81:1358-1369. 
279 Reddy, R. C., Colvin, J., Muniyappa, V., \& Seal, S., 2005. Diversity and distribution of 280 begomoviruses infecting tomato in India. Archives of virology, 150(5), 845-867.

281 Sadeq Al-Kuwaiti, N. A., 2013. Molecular characterization of viruses infecting potato and 282 vegetables in Iraq (Doctoral dissertation, University of Greenwich).

283 Salati, R., Nahkla, M. K., Rojas, M. R., Guzman, P., Jaquez, J., Maxwell, D. P., \& Gilbertson, R. 284 L., 2002. Tomato yellow leaf curl virus in the Dominican Republic: characterization of an 285 infectious clone, virus monitoring in whiteflies, and identification of reservoir 286 hosts. Phytopathology, 92(5), 487-496.

287 Saunders, K., Norman, A., Gucciardo, S., \& Stanley, J., 2004. The DNA $\beta$ satellite component 288 associated with ageratum yellow vein disease encodes an essential pathogenicity protein 289 ( $\beta \mathrm{C1}$ ). Virology, 324(1), 37-47.

290 Tamura K., Stecher G., Peterson D., Filipski A. \& Kumar S., 2013. MEGA6: molecular 291 evolutionary genetics analysis version 6.0. Molecular Biology and Evolution 30, 2725- 2729.

292 Varsani, A., Roumagnac, P., Fuchs, M., Navas-Castillo, J., Moriones, E., Idris, A., ... \& Martin, 293 D. P., 2017. Capulavirus and Grablovirus: two new genera in the family

294 Geminiviridae. Archives of Virology, 162(6), 1819-1831.

295 Yang, Z., Mammel, M., Papafragkou, E., Hida, K., Elkins, C. A., \& Kulka, M., 2017.

296 Application of next generation sequencing toward sensitive detection of enteric viruses isolated 297 from celery samples as an example of produce. International journal of food microbiology, 261, $298 \quad 73-81$.

299 Yang, X., Xie, Y., Raja, P., Li, S., Wolf, J. N., Shen, Q., et al., 2011. Suppression of 300 methylation-mediated transcriptional gene silencing by $\beta \mathrm{C} 1-\mathrm{SAHH}$ protein interaction during 301 geminivirus-betasatellite infection. PLoS Pathog. 7:e1002329. doi:

302 10.1371/journal.ppat.1002329.

303 Zhou, X., 2013. Advances in understanding begomovirus satellites. Annual review of 304 phytopathology, 51.

$305 \quad$ Figures 

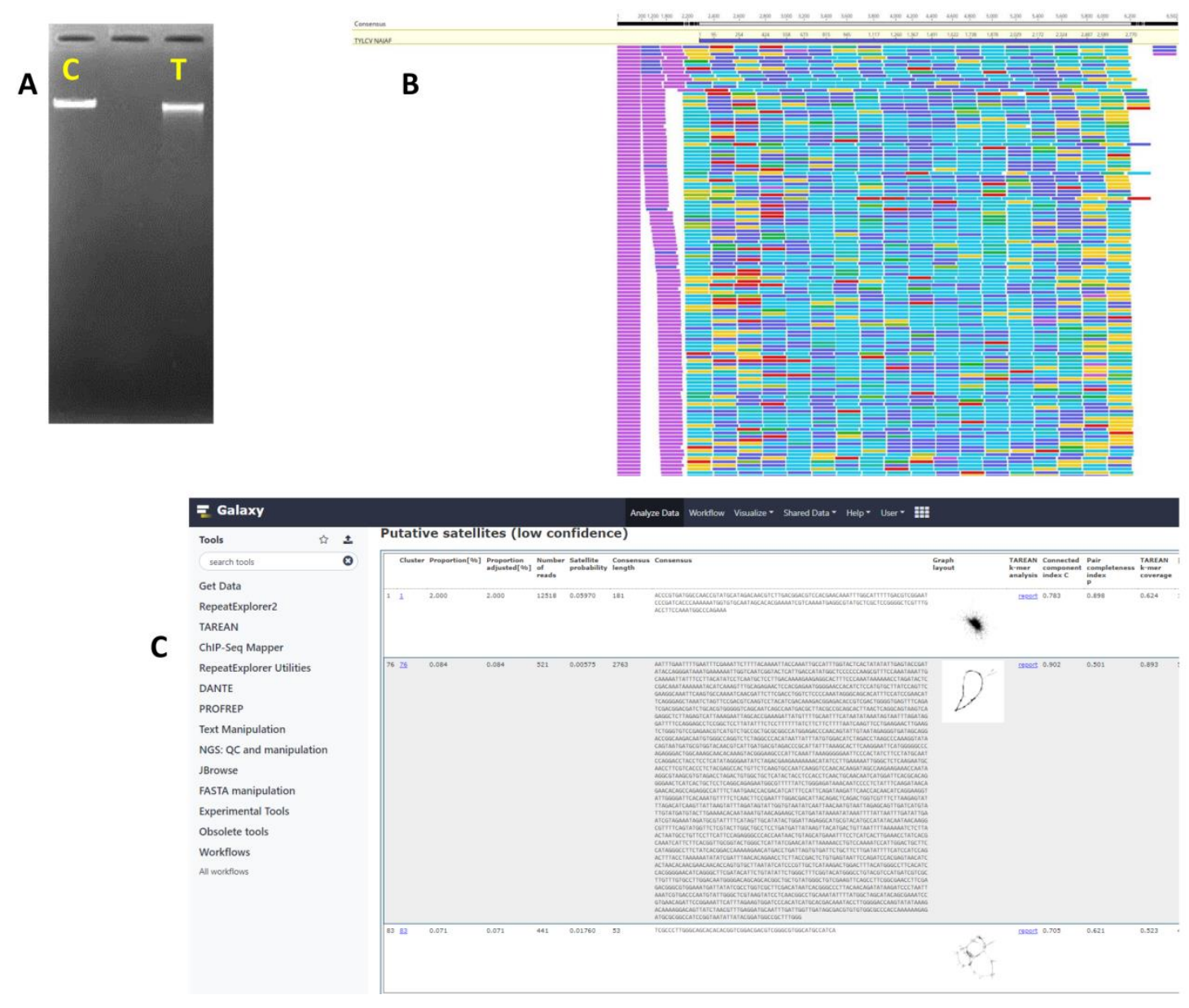

Fig. 1. A: Gel electrophoresis of genomic DNA of TYLCV-infected tomato var. Oula F1 (T), in comparison with a control genomic DNA (C). B: Raw reads mapped to complete sequence of TYLCV-Najaf isolate (2770 nt), the assembled reads were 65,303 that used to calculate genome proportion and copy numbers. C: RepeatExplorer report showed cluster number 76 for TYLCV sequence $(2763 \mathrm{nt})$ that picked up as a putative satellite due to tandemly arranged feature within raw reads. 


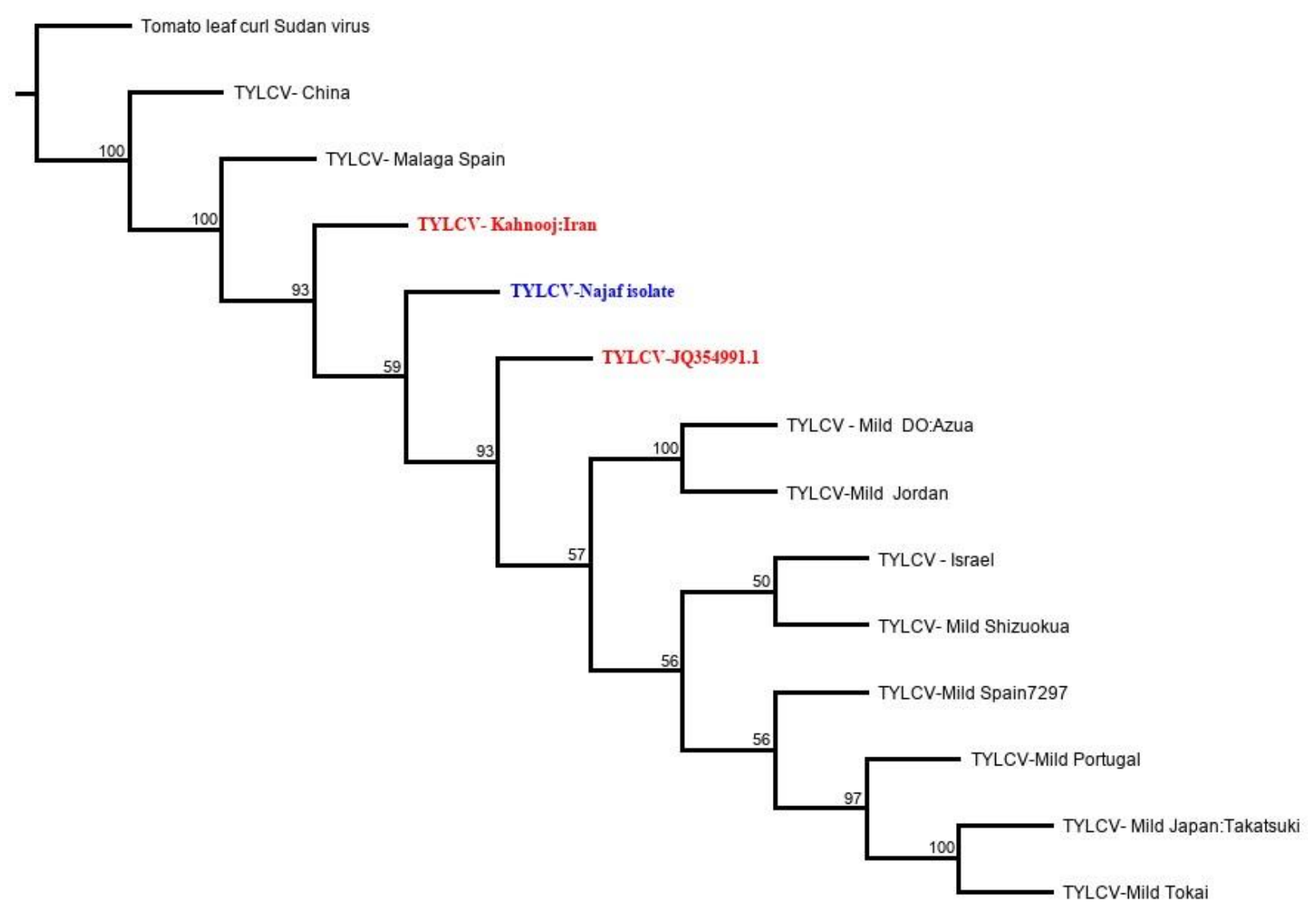

Fig. 2. Phylogenetic tree of 13 full lengths TYLCV isolates showing close relationship between Najaf and Kahnooj isolates. The tree was generated using Geneious tree builder with bootstrape analyses and 50\% support, the out group member was Tomato leaf curl Sudan virus.

Words count: 3566 